\title{
Antecedentes a la intervención de Estados Unidos en la guerra europea desde la perspectiva de la diplomacia española
}

José María Marín Arce

A partir de la primavera de 1916 tanto EE.UU. como los Imperios Centrales, aunque desde posiciones bien distintas y por intereses lógicamente diferentes, coinciden en impulsar diversas propuestas de paz que acaben con la ya larga y costosa guerra europea.

Las inesperadas derrotas austríacas en el frente ruso, que produjeron el subsiguiente abandono de la ofensiva contra Italia durante el mes de junio, junto a la declaración de guerra del reino de Rumanía a la monarquía austro-húngara y de Italia a Alemania complicaron las posiciones militares de los Imperios Centrales, impulsándoles a buscar un acuerdo de paz que pusiera fin a la guerra. Su propósito no era otro que entablar negociaciones tratando de mantener la ocupación de los reinos de Bélgica, Servia y Montenegro, de toda Polonia, de varias provincias rusas y algunos de los Departamentos más ricos de Francia; sin embargo, esto chocaba con la fundamentada esperanza de los aliados en conseguir la victoria final, $y$, por tanto, su oposición a cualquier acuerdo de paz que no supusiera la claudicación alemana '.

Los reveses militares sufridos por los Imperios Centrales coinciden con graves problemas internos principalmente en Austria-Hungría y Turquía. La débil unión monárquica entre Austria y Hungría amenaza con

${ }^{1}$ Archivo Romanones: Leg. $30, n .{ }^{\circ} 4$, telegrama de Polo, embajador español en Berlín, a Romanones, 26-6-1916. 
desatarse por las dificultades económicas, el enfrentamiento del Parlamento húngaro con las autoridades austriacas y, sobre todo, la intromisión de los alemanes en la política interior austriaca que produce una profunda disgregación entre los partidos políticos duramente enfrentados ante el cada vez mayor control germánico sobre el Imperio.

Aun cuando en el mes de septiembre los ejércitos austro-húngaros han conseguido resistir las ofensivas rusa, rumana e italiana, continúa la grave crisis política y económica. El Parlamente húngaro, única institución liberal que funciona en la doble monarquía desde que comenzó la guerra, había emprendido una violenta campaña contra el conde Tisza, Presidente del Consejo de Ministros de Hungría, el conde Stürgk, Presidente del Consejo austríaco y, sobre todo, el barón Burián, ministro de Negocios Extranjeros del Imperio, que con sus medidas económicas dirigidas a paliar la crisis de subsistencias perjudicaba la tradicional unión aduanera entre Austria y Hungría. Encabezaba la oposición húngara el conde Audrassy, jefe del partido constitucional, decidido a sustituir al barón Burián, y enturbiaba, aún más, la situación el conde Karolyí, fundador del partido de la independencia, enemigo acérrimo de Alemania y partidario de negociar cuanto antes una paz que garantizase la integridad territorial de Hungría. En Austria se produjo un movimiento paralelo en contra del conde Stürgk en el que participaban miembros del partido pangermanista y que trabajaba por la reapertura del Parlamento austríaco cerrado desde el primer semestre de 1914. Fiel reflejo de la situación en Austria-Hungría es $\epsilon !$ informe que A. de Castro, embajador español en Viena, envía al Presidente del Consejo, conde de Romanones, y en el que aboga por la acción conjunta de los países neutrales para que presenten a los beligerantes unas proposiciones de paz, basadas, no en arrogancias ni exigencias, sino en mutuas concesiones que permitan someter a un tribunal, formado también por países neutrales, las dificultades derivadas de las rectificaciones de fronteras. Desde Budapest el barón Burián, responsable de la diplomacia Austro-Húngara, en declaraciones al diario Budapesty Hyrlap, se mostraba igualmente favorable a una iniciativa de paz "honrosa" que "ni esta Monarquía - afirmaba- ni Alemania, desaprovecharían" ${ }^{2}$.

En Turquía la situación militar y el estado interior es francamente precario, más aún después de la declaración de guerra por parte de

${ }^{2}$ Ibidem, Leg. 22, n. ${ }^{\circ}$, cartas de A. de Castro, embajador en Viena, a Romanones, 8-8-1916, 19-9-1916 y 26-9-1916. El imparcial, 1-8-1916, artículo de Salvador de Madariaga, corresponsal en Londres. 
Rumanía. Las divisiones internas cada vez son mayores y mientras que el ministro de la Guerra y el de Negocios Extranjeros respaldan la continuación de la guerra, estableciendo mayores vínculos con sus aliados alemanes y austríacos, los partidarios de una paz por separado aumentan y el movimiento árabe contrario a cualquier alianza europea adquiere cada vez más importancia. A mediados de diciembre, junto a Alemania y Austria-Hungría, los gobiernos turco y búlgaro envían una nota, a través de los países neutrales, a los aliados proponiendo entrar en negociaciones de paz ${ }^{3}$.

Consecuentemente con las dificultades militares y la necesidad de una tregua que alivie la grave crisis de subsistencias y recomponga la política interior de los Imperios Centrales, el Canciller Alemán Bethamann-Hollweg, el 12 de diciembre de 1916, envía, por conducto de los países neutrales EE.UU., España y Suiza, una propuesta de apertura de negociaciones que conduzcan al fin de la guerra. La contestación de los países aliados a la proposición alemana fue contundentemente negativa, sin dejar el más mínimo resquicio a un posible convenio futuro de paz. El documento firmado en París el 30 de diciembre de 1916 por los gobiernos de Bélgica, Francia, Gran Bretaña, Italia, Japón, Montenegro, Portugal, Rumanía, Rusia y Servia, refleja muy exactamente cuál es la posición de los países de la Entente y cuál es su idea de un eventual término de la guerra, más parecido a una rendición sin condiciones de los Imperios Centrales que a un acuerdo negociado de paz honrosa.

Los aliados pretenden que Alemania y sus coaligados reconozcan su culpabilidad en la declaración del conflicto, en la ocupación ilegal de países neutrales como Bélgica, en la vulneración de todo tipo de tratados internacionales y en toda serie de crímenes de guerra: guerra submarina, deportaciones, trabajos y alistamientos obligatorios de personas contra sus propios países y violaciones de neutralidad. Recuerdan que todos los afanes encaminados a conseguir la paz desde el comienzo de la guerra han sido boicoteados por los Imperios Centrales. Por ello, no ven en la propuesta alemana otra cosa que «una premeditada tentativa con el fin de apoyarse en la evolución de la guerra e imponer finalmente una paz alemana» que modificaría sustancialmente el mapa europeo en beneficio de la política anexionista de Alemania. Además, los países de la Entente

${ }^{3}$ Ibidem, Leg. 22, n. ${ }^{\circ}$, telegrama de A. Castro a Amalio Gimeno, ministro de Estado, 22-7-1916, 10-9-1916 y 28-10-1916; Leg. 16,.$^{\circ} 5$, telegrama de Saavedra, ministro de España en Sofía, a Amalio Gimeno, 15-12-1916. 
denuncian que la pretendida proposición de paz está desprovista de contenido y precisión, siendo más bien una maniobra de guerra que un ofrecimiento pacífico.

Están tan seguros los aliados de una victoria final que no aceptan otra cosa que no sea la capitulación germánica en condiciones tan desohonrosas que impongan a Alemania todo tipo de sanciones, reparaciones y garantías, por "los innumerables atentados cometidos contra beligerantes y neutrales». Esta será, con matices, la posición mantenida por Gran Bretaña, Italia y, sobre todo, Francia una vez finalizada la guerra.

Los Estados Unidos desde el torpedeamiento alemán a los buques mercantes, que puso en grave peligro la libertad de los mares, quiso servir de intermediario entre las potencias beligerantes $y$, cuanto antes, poner término a una guerra que si bien al principio había producido cuantiosos beneficios económicos ahora amenazaba con colapsar el comercio americano con Europa. Ya a fines de mayo, el embajador americano en Berlín habla de la conveniencia de llegar en breve a la paz y propone como primera condición la convocatoria de una conferencia, a celebrar en El Haya, de los países neutrales para examinar las reglas de derecho marítimo internacional, claramente rotas por Alemania, y desde allí avanzar en una propuesta de paz que pudiera ser aceptada por los países beligerantes. Paralelamente, el presidente de EE.UU., argumentando las penalidades sufridas por los neutrales, habla de la necesidad del cese de la guerra en Europa ${ }^{4}$.

El 22 de diciembre, a los pocos días de la nota alemana, Wilson, Presidente de EE.UU., erigiéndose defensor de los intereses de los países neutrales seriamente dañados por los efectos de la guerra, envía un comunicado a los países contendientes en el que ofrece sus buenos oficios para llegar, lo más pronto posible, a un acuerdo de paz. La posición norteamericana es tan ambigua que sólo pide a las naciones en guerra una declaración pública de sus puntos de vista respectivos en lo referente a las condiciones conforme a las cuales la guerra pudiera terminarse. Como el mismo comunicado explica, Wilson «no propone la paz, no ofrece siquiera una mediación; propone solamente que se hagan ex-

${ }^{4} \mathrm{Ibidem}$, Leg. 30, n. ${ }^{\circ}$, carta de Polo a Romanones, 26-5-1916; Leg. 16, n. ${ }^{\circ} 11$, telegrama de Merry del Val, embajador en Londres, a Romanones, 1-6-1916. 
ploraciones a fin de llegar a saber, tanto los neutrales como los beligerantes, a qué distancia nos encontramos aún del puerto de la paz".

Lo más importante de la nota de EE.UU. no era su imprecisa propuesta pacificadora sino el momento en que se dio y las consideraciones que contenía. El propio Wilson reconocía la inoportunidad de hacerla coincidir con la invitación de paz de los Imperios Centrales y aunque negaba rotundamente cualquier vinculación con la misma quiso convencer a los países aliados de que su propuesta no era contradictoria con la alemana. En modo alguno establece diferencia entre países agresores y agredidos, sosteniendo que "los hombres de Estado de los dos bandos tienen en esta guerra objetivos que son virtualmente los mismos» y por lo tanto no ha lugar ningún tipo de sanción hacia Alemania. No hace tampoco ninguna mención a las ocupaciones territoriales, ni al incumplimiento de los tratados internacionales por parte de Alemania, a pesar de ser los EE.UU. un país directamente afectado por la guerra naval. Por último es importante resaltar que Wilson, preocupado por eliminar del horizonte cualquier posibilidad de que se reproduzcan guerras como ésta, propone la formación de una «Liga de Naciones para asegurar la paz y la justicia en el Mundo entero».

Desde Alemania, la mediación de EE.UU., aunque despierta al principio una fuerte desconfianza, pues se piensa que Wilson, en realidad, es sólo un valedor de Inglaterra, a medida que transcurren los meses la necesidad se impone a las sospechas y se comienza a pensar que esa intervención pude conducir a una paz aceptable ${ }^{5}$. Así, el Gobierno alemán, al igual que Turquía, Austria-Hungría y Bulgaria, reciben con auténtico regocijo la «generosa» propuesta de Wilson y el 27 de diciembre contestan al Presidente americano aceptando su mediación y manifestando el deseo de una inmemediata reunión de los Estados beligerantes en una ciudad neutral. Por otra lado, los alemanes, conscientes de que el verdadero motivo que impulsa a los norteamericanos es el restablecimiento de la libertad de comercio, mantienen el bloqueo marítimo e incrementan el torpedeamiento de buques yanquis. Peligrosa política, pues si bien en un primer momento esto impulsa a EE.UU. a buscar con ahínco la paz, termina abocándoles a intervenir en la guerra.

Como es natural, los países aliados rechazan la propuesta de Wilson en la que ven únicamente la defensa de los intereses comerciales nortea-

${ }^{5}$ Ibidem, Leg. 30, n. ${ }^{\circ}$, carta de Polo a Romanones, 26-5-1916. 
mericanos y la sospechosa coincidencia con el propósito de paz alemán. No pueden aceptar además que se trate por igual a los paises en guerra, pues esto choca frontalmente con los planes aliados de asegurarles las reparaciones, restituciones y garantías a que les da derecho la agresión, cuya responsabilidad recae sobre las potencias centrales. $Y$ también una inmediata tregua daría un tiempo precioso a los Imperios Centrales para recuperar fuerzas y volver con más ímpetu a romper las hostilidades. En la nota de contestación a Wilson, los aliados, engreídos por las últimas victorias militares, plantean una serie de reivindicaciones imposibles de aceptar por los alemanes si no es por la fuerza de las armas ${ }^{6}$.

El rechazo francés a Wilson es manifiesto. Tanto por parte del Gobierno como de la opinión pública — según relata el embajador español en París-, "se ha tomado muy mal la nota americana», se piensa que los EE.UU., que forman parte de otro continente, tienen otra diplomacia y otras aspiraciones que las naciones occidentales de Europa y pueden permitirse sin peligro una gestión semejante que favorece claramente a Alemania. Cambon, ministro francés de Asuntos Exteriores, quiere quitar hierro al asunto y declara que, por conocer bien a los americanos, no concedía tanta importancia a la nota, atribuyéndola «a un movimiento de vanidad de Wilson y también al temor de la campaña de los submarinos anunciada para el primero de enero". La posición francesa, coincidente con la inglesa, es de continuar la guerra rechazando cualquier gestión de paz incluso la proveniente de un país neutral como España. Los representantes diplomáticos franceses, acreditados en los países neutrales, recibieron órdenes terminantes y severas de decir a los gobiernos de esos países que toda gestión apoyando la paz realizada en estos momentos sería muy mal acogida ${ }^{7}$.

En Inglaterra, desde que comenzaron en primavera de 1916 los rumores de mediación norteamericana, el rechazo a la negociación es total. La nación entera se halla completamente decidida a prolongar la lucha, el sólo hablar de paz se considera traición y cualquier maniobra que tienda a ello es atribuida a Alemania. Esta actitud se confirma cuando ya es oficial, en diciembre de 1916, la nota norteamericana.

${ }^{6}$ Respuesta de los aliados al Presidente Wilson, firmada en París el 10-1-1917.

7 Archivo Ramanones: Leg. $16, \mathrm{n}^{\circ}$ 8, telegramas de León y Castillo, embajador en París, a Romanones, 22, 23 y 26-12-1916. 
La hostilidad hacia Wilson es ostensible. No se le perdona la iniciativa espontánea que sólo beneficia a Alemania y se critica duramente a los EE.UU. que utilicen sus importantes medios económicos y militares para imponer su voluntad cuando se han lucrado inesperadamente con la guerra.

La opinión del embajador español en Londres es terminante: «puedo asegurar autorizadamente a V.E. (Romanones) que este Gobierno se ha sentido ofendido por iniciativa intempestiva y falta de tacto del Presidente de EE.UU." Aunque el Gobierno inglés oficialmente rechaza cualquier formulación de paz, no quiere esto decir que su diplomacia carezca de una líneas básicas que permitan avanzar hacia el término de la guerra. Merry del Val resume la actitud general británica en los siguientes puntos: Primero, no rehusar la paz, en principio, pero exigir que Alemania formule proposiciones para ver si concuerdan con lo admisible por los aliados. Segundo, desconfiar de toda conferencia internacional. Tercero, establecer un sistema para evitar en el futuro la guerra, siempre y cuando las potencias fundadoras o participantes en el acuerdo se comprometan a mantenerlo o impongan su respeto con las armas cuando sea necesario. Y cuarto, prescindir, por el momento, de la intervención de los países neutrales para precipitar negociaciones de paz. Bien entendido que todo esto no era contradictorio con la acción militar, eje fundamental de la política exterior inglesa ${ }^{3}$.

En Italia, país recientemente implicado en la guerra, al igual que en los países aliados, la gestión americana es mal acogida por el Gobierno y por la prensa, con la excepción del Pueblo Romano, diario germanófilo a sueldo de la embajada alemana. Sonnino, ministro de Asuntos Exteriores, explica a Villaurrutia, embajador español en el Quirinal, que «a su juicio la nota de América no tenía probabilidad alguna de éxito. Pecaba de inoportuna; primero, porque no estaban las cosas maduras para negociar la paz; segundo, porque después de presentada la nota alemana parecía, aunque no lo fuera, secuela de aquél, y tercero, porque si bien no estaba todavía redactada la respuesta a la nota alemana habíala ya dado negativa" ${ }^{9}$.

Si el Gobierno italiano censura la iniciativa americana por considerar que servía a los intereses de Alemania, también condena la ambigua

${ }^{8}$ Ibidem, Leg. 16, $\mathrm{n} .{ }^{\circ} 11$, telegramas de Merry del Val a Romanones y Amalio Gimeno, 1-6-1916, 26-12-1916, 28-12-1916.

${ }^{9}$ Ibidem, Leg. 16, n. ${ }^{\circ} 10$, telegrama de Villaurrutia a Romanones, 26-12-1916. 
posición del Vaticano que no se compromete en favor de la paz, limitándose a votos y generalidades de rigor, haciendo todo lo posible para que los neutrales apoyen a Wilson y así - en opinión de Sonnino- una vez fracasadas las gestiones americanas, ser los únicos, el día de mañana, que pudieran presentarse ante los beligerantes sin haberse gastado en operaciones frustadas y como país capaz de proponer la paz ${ }^{10}$. De la correspondencia entre Calbetón, embajador español en la Santa Sede, y Romanones deducimos que las opiniones de Sonnino no andan descaminadas. Tanto el Pontífice como el Cardenal Secretario de Estado quieren utilizar la diplomacia española como valedora ante Inglaterra, muy reticente al comportamiento vaticano que considera aliado de Alemania y de EE.UU. También presionan al Gobierno español para que promocione las propuestas de paz de los Imperios Centrales, primero, y de Wilson, después. Tratan, además, de acercar la política exterior española a Berlín, separándola lo más posible de París y Londres ${ }^{11}$.

Rusia, a pesar de que sus ejércitos están francamente mermados y millares de soldados desertan a sus hogares, por boca de su Emperador declara que el momento de la paz no ha llegado y que cualquier negociación ha de garantizar a su país la ocupación de Constantinopla y Dardanelos -fundamental para el paso al Mediterráneo- y la creación del reino de Polonia compuesto de las tres divisiones de dicha antigua Monarquía ${ }^{12}$.

La disposición de los países neutrales tuvo notables diferencias. Suiza, profundamente interesada en el fin de la guerra, apoya incondicionalmente y desde el principio la propuesta americana, manteniéndose en una escrupulosa equidistancia entre los aliados y los Imperios Centrales ${ }^{13}$.

Entre los países escandinavos, aunque al final terminan todos apoyando el plan Wilson, las posiciones no fueron del todo homogéneas. El Gobierno sueco es el principal valedor americano, ordenando a sus embajadores en Madrid, La Haya, Berna, Copenhagen y Christiania que bus-

${ }^{10} \mathrm{Ibidem}$, Leg. $16, \mathrm{n} .{ }^{\circ} 10$, telegrama de Villaurrutia a Romanones, 26-12-1916.

11 Ibidem, Leg. 16, n. ${ }^{\circ} 15$, telegramas de Calbetón, embajador én el Vaticano, a Romanones, 11-5-1916, 3 a 27-12-1916, 23-1-1917.

${ }^{12}$ Ibidem, Leg. $16, n .^{\circ} 11$, telegrama de Villasinda, embajador en Rusia, al ministro de Estado, 30-12-1916.

${ }_{13}$ Ibidem, Leg. 16, n. ${ }^{\circ}$ 13, correspondencia entre Reynoso, embajador en Berna, y Amalia Gimeno. 
quen el apoyo de los neutrales. Es tan clara la actitud de Suecia y tan conocidas sus amistades tanto con EE.UU. como con Alemania, que Inglaterra amenaza a su Gobierno con «el resentimiento grave de las relaciones entre ambos países ahora y en el futuro» ${ }^{14}$.

Dinamarca y Noruega, si bien al principio se muestran reticentes prefiriendo mantenerse al margen, terminan cediendo a la presión sueca que les intimida con la ruptura de la unión escandinava. El Gobierno holandés calificó la iniciativa de Wilson de desacertada e inoportuna, y rechazó apoyarla mientras no lo hicieran todos los países neutrales ${ }^{15}$. Coincide bastante con la realidad la opinión que los alemanes tienen de estos países neutrales: «En Suecia -explica Von Jagov, ministro de Negocios Extranjeros, al Consejo de ministros alemán- el Gobierno y las grandes industrias son los únicos que están con nosotros. Noruega nos es hostil. En Dinamarca, el Ministerio actual está con nosotros y la nación contra nosotros. Holanda está francamente al lado de los aliados. Y Suiza no va precisamente al lado de nuestros enemigos, pero está más bien contra nosotros» ${ }^{16}$.

La posición de España, como país neutral, adquiere, en este año 1916, una cierta relevancia en el contexto europeo que irá decayendo desde la intervención norteamericana en la guerra al comienzo de 1917. La política exterior en manos de un gobierno liberal va basculando progresivamente hacia posiciones cada vez más aliadófilas. No fue esto fácil para Romanones, Presidente del Gobierno, que tuvo que luchar contra un sector de la opinión pública claramente germanófilo y tuvo además que controlar lo más posible una diplomacia dividida entre los partidarios de un mayor acercamiento a Alemania y los adeptos a emprender una acción exterior más de acuerdo con Francia e Inglaterra. Parecía como si los embajadores en Europa, contrarios todos ellos a la mediación americana, compitieran entre sí para que Alfonso XIII ocupara el papel de intermediario en el conflicto europeo. A. de Castro, embajador de Austria, propone a Romanones que el Rey, emparentado con la familia imperial austríaca y con la real de Inglaterra, asistiese al entierro de su tío el Emperador Francisco José, fallecido el 21 de noviembre de 1916, y

${ }^{14} \mathrm{Ibidem}$, Leg. 16, $\mathrm{n} .{ }^{\circ}$ 12, telegramas de Amalfi, embajador en Suecia, al ministro de Estado; Leg. 16, n. ${ }^{\circ} 11$, telegrama de Merry del Val al ministro de Estado, 24-12-1916.

${ }^{15}$ Ibidem, Leg. 16, n. ${ }^{\circ} 6$, telegramas de Agüera, ministro de España en Copenhague y El Haya, al ministro de Estado, 29-12-1916, 5-1-1917.

${ }^{16} \mathrm{Ibidem}$, Leg. $35, \mathrm{n}^{\circ}$ 6, telegrama de León y Castillo, embajador en París, a Romanones, 27-6-1916. 
desde allí preparar un acuerdo de paz. No sólo tuvo Romanones que quitar de la cabeza a su embajador tan peregrina idea, que descabalaba la política exterior, sino que tuvo que enfrentarse con el propio Rey, empeñado en viajar a Austria. Natalio Rivas cuenta en su diario que Alfonso XIII le dijo al Presidente del Gobierno: «He resuelto contra tu consejo o sin él, marchar a Viena a asistir al entierro y como allí estará el Emperador de Alemania hablaré con él. Regresaré por París y de estas conferencias puede surgir el que yo sea el árbitro de la paz". Por fin Romanones con el apoyo de Alba pudo disuadir al monarca, pero enseguida volvieron a surgir las desaveniencias y esta vez por un asunto de "protocolo"; véamos el relato de Natalio Rivas:

\begin{abstract}
«Ayer tarde, 4 de diciembre, víspera de los funerales, el Rey manifestó a Romanones que asistiría vestido con uniforme de general austriaco. Romanones y Alba deciden mandar una carta al Rey manifestándoles terminantemente que el Gobierno era opuesto a su resolución, dándole a entender que de no seguir su consejo, sería caso de crisis... El Rey con buen acuerdo vistió el uniforme de Capitán Gral. español» ${ }^{17}$.
\end{abstract}

Cuando surge la propuesta de paz norteamericana los Gobiernos francés e inglés piden al Gobierno español que no apoye dicha propuesta. Aunque la opinión pública española, y sobre todo la prensa, estaba dividida en torno a este asunto -mientras los germanófilos se declaraban favorables al plan de Wilson, los medios aliadófilos denunciaban el intento pacificador como maniobra alemana-, a Romanones le fue sencillo negarse a los planes yanquis argumentando la inoportunidad de los mismos y la falta de eficacia al contar con la manifiesta oposición de los aliados ${ }^{18}$.

Por otra parte, la campaña alemana de torpedeamientos a buques españoles coadyuvó extraordinariamente a un mayor acercamiento a los países aliados. En esta línea, una vez que había fracasado el plan Wilson y estando el Vaticano imposibilitado de hablar con Italia y Francia, Romanones ofrece a los aliados la mediación española en la guerra. Tanto Francia como Inglaterra e Italia, firmemente decididos a continuar la gue-

17 Ibidem, Leg. 22, n. 1 , telegrama de A. Castro a Romanones, 8-12-1916. Archivo Natalio Rivas: Leg. 11-8903, diario 5-12-1916.

${ }^{18}$ Ibidem, Leg. 16, n. ${ }^{\circ 5} 8$ y 11, telegramas de León y Castillo y Merrry del Val a Romanones. 
rra, rechazan cualquier intromisión de los países neutrales y, por lo tanto, de España ${ }^{19}$.

Frustrada la proposición de paz americana, los aliados se preparan para una nueva ofensiva militar convocando a primeros de enero de 1917 en Roma un gran Consejo de Guerra, donde participarán los presidentes de los Gobiernos aliados junto a ministros de la Guerra y generales que constituyen los gabinetes militares. Paralelamente los EE.UU. empiezan a hablar de la necesidad de renovar la guerra para traer la libertad de los mares y el comercio ${ }^{20}$ y Alemania declara el 31 de enero de 1917 que aumentaría la guerra submarina.

En respuesta a esta amenaza, el 3 de febrero el presidente Wilson anuncia la ruptura de relaciones diplomáticas con Alemania y dos meses después, tras el torpedeo alemán al buque "Vigilantia», el Congreso de los EE.UU. aprueba el día 2 de abril la declaración de guerra y la participación militar americana en el conflicto europeo.

La entrada de EE.UU. en la guerra provoca el aislamiento de la política exterior española además de graves problemas económicos. El bloqueo submarino, extendido ahora a casi todos los países neutrales con los que España puede comerciar, amenaza con colapsar el tráfico marítimo $\mathrm{y}$, por ende, las pingües ganancias de los navieros vascos enriquecidos con el aumento extraordinario de los fletes hasta 1917. Por otra parte, los países aliados recriminan al Gobierno español la condescendencia hacia las actividades alemanas en la Península y en Marruecos (contrabando de armas, depósito de explosivos en Cartagena, espionaje, dinero y armas a las kábilas marroquíes para excitarles en su lucha contra Francia, etc...) y, sobre todo, la falta de contundencia en contestar al continuo torpedeamiento alemán a buques españoles ${ }^{21}$.

Romanones, muy consciente de este aislamiento internacional y de la carencia de perspectivas de la política exterior, se mostró partidario de acabar con el status de neutralidad que España había mantenido desde

${ }^{19}$ Ibidem, Leg. 16, $\mathrm{n} .{ }^{\circ}$ 8, telegrama de León y Castillo a Romanones, 26-12-1916; Leg.

$16,{ }^{\circ}{ }^{\circ} 11$, telegrama de Merry del Val a Romanones, 29-12-1916.

${ }^{20} \mathrm{lbidem}$, Leg. 16, n. ${ }^{\circ}$ 7, telegramas de Riaño, embajador en EE.UU., a Romanones, $20,22,24$ y $29-12-1916$.

${ }_{21}$ Ibidem, Leg. 35, n. ${ }^{\circ}$ 6, telegramas de León y Castillo a Romanones, 5, 8, 10-2-1917 y 4-4-1917. 
1914 y, aun sin proponer la entrada en la guerra, establecer una mayor alianza con Francia e Inglaterra.

Pero este cambio de política no fue seguido por el resto del Gabinete y a su Presidente le faltó el apoyo de una parte de su partido y de la mayoría de los liberales ${ }^{22}$. En tal situación, Romanones, el 20 de abril, entregó al Rey una nota memorandum, en la que explicaba su cambio de postura respecto a Alemania y presentaba irremisiblemente su dimisión ${ }^{23}$.

Si bien los romanonistas entendieron que la crisis gubernamental se debía exclusivamente a la división de los liberales al apreciar el modo de entender la neutralidad, no podemos olvidar que el gobierno liberal, presidido por Romanones, había fracasado en casi todos los terrenos. Alba, ministro de Hacienda, no pudo evitar que su proyecto de ley de beneficios extraordinarios de la guerra fuera rechazado en el Congreso y la huelga general del 18 de diciembre de 1916 -preludio de la huelga de 1917- puso de manifesto la grave crisis de subsistencias y el aumento de los precios que habían hecho descender considerablemente el nivel de vida de los trabajadores, mientras que numerosas empresas habían visto dispararse sus beneficios a raíz de los negocios hechos con la guerra.

${ }^{22}$ El presidente del Congreso, Miguel de Villanueva, había reafirmado su neutralismo, negándose a cualquier cambio en las relaciones exteriores a pesar de las agresiones alemanas. Se comentó también que García Prieto había discrepado muy seriamente de la nota que Romanones había presentado al Consejo de Ministros el 18 de abril, censurando, en términos demasiado fuertes, a Alemania por el hundimiento de barcos españoles. Igualmente se dijo de Alba que creía absurda, desatinada y suicida la política exterior y que sus relaciones con el Presidente se encontraban muy deterioradas. Y Alcalá Zamora, quizá el liberal más crítico a la política de acercamiento a los aliados, se situó en el extremo opuesto a Romanones. MARIN ARCE, Jose M. ${ }^{2}$ : El liberalismo en la crisis del sistema parlamentario español. Tesis Doctoral, UNED, Madrid 1987, págs. 95-96.

${ }^{23}$ Romanones resumia así sus posiciones: $" 1 .^{\circ}$ Notificar al Imperio Alemán que el torpedeamiento de otro barco español cualquiera que sea su destino implicaría el rompimiento de las relaciones diplomáticas entre ambos Estados; $2 .^{\circ}$ Adoptar las previsiones necesarias para garantizar con los intereses alemanes existentes en nuestro país el resarcimiento de los perjuicios que indebidamente se nos infieran; $3 .^{\circ}$ Proceder enérgicamente contra los alemanes que abusen de la hospitalidad que en España reciben cualquiera que sea su condición y $4 .{ }^{\circ}$ Estrechar las relaciones con los aliados, prosiguiendo la política exterior que la guerra vino a suspender pero no a rectificar". Archivo Romanones: Leg. 63, n. ${ }^{\circ} 46$. 